TABLE IV.

Animals of which a Positive Test has not been obtained (see footnote) with OI cc. of Serum, and the Results of Bacteriological Tests of Specimens from them.

\begin{tabular}{|c|c|c|c|c|c|}
\hline $\begin{array}{l}\text { Agglutindtion } \\
\text { Titre of } \\
\text { Blood Serum. }\end{array}$ & Animal. & Plocenta. & $\begin{array}{c}\text { Ctevine } \\
\text { Disikirrye. }\end{array}$ & Milk. & $\begin{array}{l}\text { Number } \\
\text { of Tests. }\end{array}$ \\
\hline $1 /-$ & Dumbarton & $\begin{array}{l}\text { Guinea-pigg } \\
\text { died }\end{array}$ & $\ldots$ & - & 3 \\
\hline .025 & Banff & ... & $\ldots$ & - & 4 \\
\hline .075 & Peebles & $\ldots$ & $\ldots$ & - & 3 \\
\hline $1 /-$ & Kerry & $\ldots$ & $\ldots$ & - & 4 \\
\hline \multirow[t]{3}{*}{.05} & Bute & $\ldots$ & $\ldots$ & - & 3 \\
\hline & Orkney & $\ldots$ & $\ldots$ & - & I \\
\hline & Nairn & $\ldots$ & $\ldots$ & - & $\mathrm{I}$ \\
\hline 075 & Bedford & $\ldots$ & $\ldots$ & $\ldots$ & 3 \\
\hline $.1 /-$ & Antrim & $\ldots$ & $\cdots$ & - & 3 \\
\hline .075 & Shetland & $\ldots$ & $\ldots$ & - & 3 \\
\hline$\cdot \dot{1} \%$ & Durham & $\ldots$ & $\ldots$ & - & I \\
\hline$\cdot I /-$ & Cambridge & $\ldots$ & $\ldots$ & - & I \\
\hline \multirow[t]{7}{*}{.05} & Derby ${ }^{\circ}$ & $\ldots$ & $\ldots$ & - & 4 \\
\hline & Flint $t$ & $\ldots$ & ... & 一 & 2 \\
\hline & Tyrone & $\ldots$ & $\ldots$ & --- & I \\
\hline & Hants & $\ldots$ & $\ldots$ & - & I \\
\hline & Inverness * & $\ldots$ & $\ldots$ & - & I \\
\hline & Wigtown & $\ldots$ & $\ldots$ & - & 2 \\
\hline & Ross & $\ldots$ & $\ldots$ & - & 3 \\
\hline .075 & Worcester + & $\ldots$ & $\ldots$ & - & 2 \\
\hline$\cdot 1 /=$ & Caithness $\uparrow$ & $\ldots$ & $\ldots$ & - & 2 \\
\hline .075 & Elgin & $\ldots$ & $\ldots$ & - & 2 \\
\hline
\end{tabular}

* This animal has given a positive test since the material for the above-recorded bacteriological examination was secured.

† These animals gave a positive test followed by a negative test in the period prior to date of collection of samples for bacteriological examination.

$N . B$. - These five animals are inserted in this table simply to make the verification of the agglutination test more crucial, for the clinical and agglutination test results are parallel through the infection period and (apparently) the dying out of infection.

\title{
PSEUDO-ACTINOMYCOSIS OR STREPTOTRICHOSIS IN THE CAMEL.
}

By Major F. E. Mason, R.A.V.C., Sub-Director and Veterinary Pathologist, Veterinary Service, Ministry of Agriculture, Cairo.

IN February I9I7 a young Sudanese camel, which had recently been imported, died after a short illness at No. I Camel Hospital, Zeitoun, Cairo.

The following organs, which contained lesions having a nakedeye resemblance to tuberculous lesions, were sent for examination by Major D. S. Rabagliati, R.A.V.C.: lungs, bronchial glands, prescapular glands, liver, kidneys, and lumbar glands.

The lungs contained solid irregularly-shaped masses of a greyish colour up to the size of a broad bean and surrounded by a hamorr- 
hagic zone. Innumerable semi-translucent spherical nodules, resembling young miliary tubercles, were scattered fairly uniformly throughout the tissue of both organs.

The bronchial, prescapular, and lumbar glands contained yellowishgrey nodules. The kidneys contained numerous yellowish-grey firm areas, chiefly in the cortex and mostly wedge-shaped on radial section.

The liver also contained a few nodules with similar characters but approaching the spherical in shape.

Scrapings made from the various lesions enumerated were found on microscopic examination to contain a streptothrix fungus, which was also obtained in pure culture from several of the lesions in different organs.

It bears a close resemblance to the active vegetative elements of the genus Nocardia (actinomyces), and more particularly to Nocardia (actinomyces) convoluta, ${ }^{1}$ from which, however, it is distinct.

The fungus consists of a mycelium composed of irregularly branching hyphæe without visible sheath or segmentation. The hyphal threads are frequently of great length, but about the same width as a tubercle bacillus.

When stained by Gram's method the hyphæ may stain homogeneously, but frequently they have a beaded appearance, there being unstained or faintly stained areas in between the stained ones. Many short threads are seen, bacillary in form, some beaded and some uniformly stained. Apparently the beaded bacillary forms represent thallospores.

In lesions above those of the smallest size it was observed that the substance of the hypha tends to break up into minute granules; empty sheaths are also seen which no longer retain Gram's stain.

In many of the hyphæ, in which the method of branching off is irregular and not dichotomous, fusiform enlargements are seen measuring about $I^{\circ} 5 \mu$ in length by $I \mu$ in width, chiefly placed lengthways in the course of a hypha. Sometimes they are placed at the point of origin of a branch, and more rarely in a terminal position, giving a somewhat drum-stick appearance.

They are strongly Gram-positive and appear to represent arthrospores. Free spores are also numerous.

No club-formation was seen, no rosette, nor was any grain discoverable by the naked eye or microscope.

The term "grain" is here used in its strictest sense as defined by Chalmers and Archibald " : The word granum or grain is applied to certain coloured bodies of varying consistence, size, and shape, which are composed of hyphæ, and sometimes chlamydospores, embedded in a matrix, and which on germination give rise to mycelial filaments and are found in mycetomas."

In the absence of a grain it is evident that the fungus under discussion cannot be classified as a Nocardia or true actinomyces, but should be placed in the genus streptothrix, in which it forms a species with special characters, differing, so far as I have been able to ascertain, from all previously described pathogenic streptothrices.

1 Chalmers \& Christopherson "Annals of Tropical Medicine and Parasitology," No. 2, 1916.

${ }^{2}$ Fungi imperfecti in Tropical Medicine, London, 1915; quoted in "Annals of Tropical Medicine and Parasitology," 1916. 


\section{Staining Reactions.}

The fungus in preparations made directly from the lesions in the animal body is strongly acid-fast when stained by the Ziehl-Neelsen method, but is immediately decolorised by alcohol.

This property is not possessed by artificial cultures on ordinary media, but is regained by passage through the animal body. Lesions produced experimentally in animals by inoculation with the nonacid-fast cultures are found to contain the fungus in full possession of its acid-fast property.

It stains well by the Gram and Claudius methods.

It stains faintly with aquæous solutions of methylene blue and moderately well with Loffler's blue, gentian violet, and methyb violet.

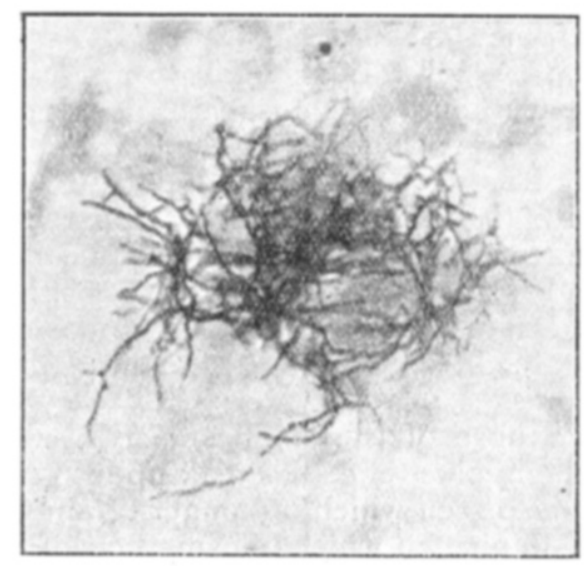

FIG. 1.

Smear preparation from lung lesion of Case I., showing the acid-fast Streptothrix cameli. Stain Ziehl-Neelsen. ( $\times 1025)$.

\section{Cultivation.}

Apparently a strict ærobe; no growth was obtained by anærobic methods.

The organism grows well on ordinary culture media at $37^{\circ} \mathrm{C}$; slow growth is obtained at $22^{\circ} \mathrm{C}$ to $25^{\circ} \mathrm{C}$.

All cultures give off a strong mouldy odour.

On agar it grows as snow-white rounded flat colonies, slightly raised in the centre, firmly adherent to the surface of the medium, in which they are shallowly embedded and leave a slight erosion when a colony is removed. At $37^{\circ} \mathrm{C}$ growth is visible in forty-eight hours. In some tubes the colonies tend to become confluent and form a rough, nodulated, snow-white membrane which is firmly adherent to the medium. The growth may remain snow-white, or it may turn slightly pink after fifteen days. Maximum growth is obtained in about twenty-five days. The colour of the medium is not altered.

On glucose-agar same as on agar; no growth in stab cultures except on the surface. 
On solid blood-serum growth is visible in forty-eight hours as minute, rounded, white colonies, firmly adherent to the medium. At seventy-two hours the colonies have increased to about $1 \mathrm{~mm}$. in diameter; at five days increased to about $2.5 \mathrm{~mm}$., with slightly darker centres and round or oval in shape. At one month the colonies are still discrete, and white or faintly pink. Medium not liquefied nor altered in colour.

In gelatine the medium becomes liquefied, and the growth is in the form of white spherical colonies which sink to the bottom.

On bouillon growth may take place at the surface, when the colonies are flat, or at the bottom, when they are spherical, or may form both at the top and bottom. The colonies are at first snowwhite. After about a week the surface growth tends to grow up the

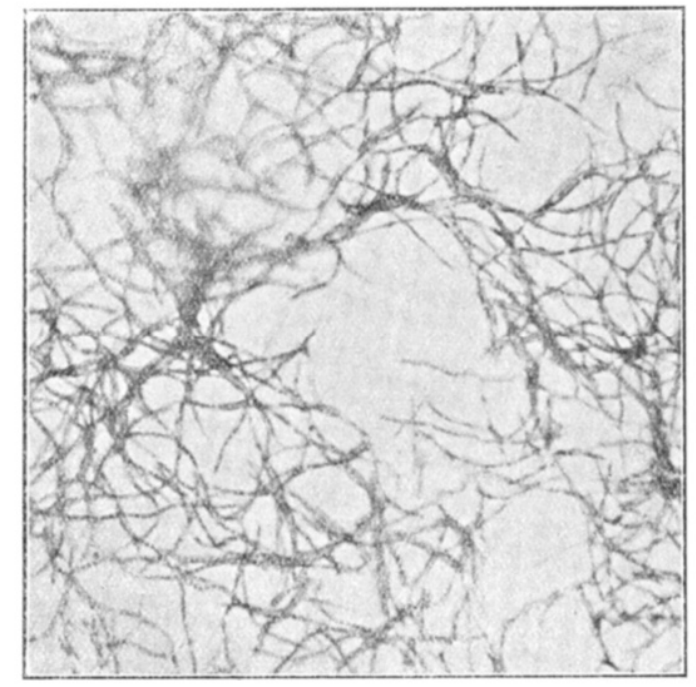

FIG. 2.

Pure culture of Streptothrix cameli five days old, showing thallospores in process of formation, hyphæ, etc. $(\times 1000)$.

side of the tube. The bouillon remains clear. After fifteen days the growth may remain snow-white or turn faintly pink. At one month the surface growth is much stronger than the deep colonies and the pink colour more marked

On potato growth occurs as a snow-white, slightly wrinkled pellicle with an irregular outline. It may remain snow-white or turn faintly pink after about fifteen days. The colour of the medium is not affected. No diastasic action was observed.

On litmus milk growth takes place at the surface and at the bottom. At seventy-two hours the litmus is not affected. At five days the milk will turn red litmus blue. At fifteen days it separates into a clear greenish fluid above and an opaque precipitate below. At thirty days the alkalinity is found to have increased five times when compared with the control litmus milk. 
On milk growth appears first on the surface; no separation at seventy-two hours. On the fifth day it turns pink, and on the next day separates into three layers of about equal depth. The top layer is translucent and brownish-pink in colour; the second layer is more opaque but lighter in colour than the top one, while the bottom layer is quite opaque and lightest in colour. After fifteen days the fungus is seen as a rich corrugated pink growth on the surface ; the milk appears as clear serum with a dense precipitate at the bottom. At thirty days no further change.

Examination of the organism grown in artificial cultures shows that it has the same characteristic streptothrix appearance as regards. the mycelia, hyphæ, beaded hyphæ, spore formation in rows, bacillus-like forms, free spores, etc., as seen in smear preparations from the fresh lesions and in sections.

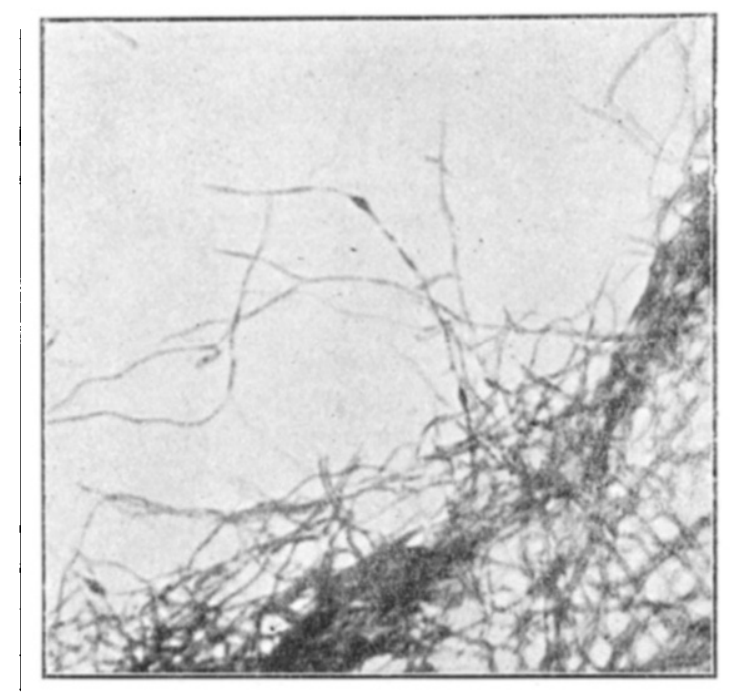

FIG. 3.

Same as Fig. 2. Shows arthrospores and thallospores.

The vegetative elements and spores from cultures are Grampositive but not acid-fast.

The spores are able to withstand desiccation; an agar culture was allowed to dry up and was kept in a dark cupboard for eight months. Sub-cultures obtained from the tube grew as well as in the first instance.

Another tube was kept in diffuse light for a month after complete drying. The spores resisted light and desiccation.

\section{The Lesions.}

The examination of a number of sections of lesions from the different organs stained by various methods showed that the fungus occupies a prominent position in every active lesion.

In the smallest lung lesions, of pin-head size, we noticed the 
fungal masses composed of hypha and spores growing along the lymph vessels in the alveolar walls. The appearance of such a lesion in section under the low power is that of a small area of lung tissue in which the alveolar walls have become several times the normal thickness, the air cells being empty. Examination under the highest powers shows that the abnormal thickness is due to the presence of masses of hyphe and spores in the thickness of the alveolar walls, from which the fungus is spreading to adjacent alveolar septa and also into the interior of the air cells themselves. Catarrhal changes are seen, the air cells becoming filled with epithelioid cells and polymorphonuclear leucocytes; the capillaries and small blood vessels are markedly congested, and actual hæmorrhages are seen in the air cells.

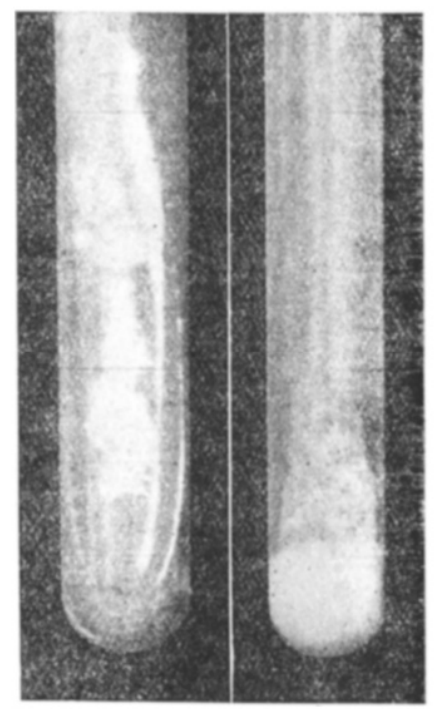

Fig. 4.

Cultures of Streptothrix came on agar and potato, ten days old. Shows snow-white colour of growth.

In the older lung lesions the fungal masses are very eviden Frequently necrotic masses of hyphæ are seen with numerous spores arranged more or less radially from the necrotic centres; masses of hyphæ which were active at the time of making the preparation are also present.

The main pathological change is broncho-pneumonia. The larger areas of consolidation show centrally an area of coagulation necrosis ; alveoli between the areas of consolidation are partly filled with serous inflammatory exudate coagulated by the action of the fixative and appearing as a finely granular material.

Many alveoli are seen to be filled with epithelioid cells and polymorphoneuclear leucocytes. Emphysematous spaces are numerous.

The pulmonary capillaries and veins are markedly engorged, and 
hæmorrhages into alveoli and emphysematous spaces are numerous As an evidence of repair, fibrous tissue is seen in its various stages.

In the kidney, the cortex is the main seat of the lesions. The fungal masses are evident, both living and necrotic, with many spores. The centre of the lesion is usually an area of coagulation necrosis surrounded by a dense infiltration of polymorphonuclear cells. The tubules in the vicinity of a lesion show desquamation of the epithelium or may be filled with serous exudate. The cortex is in a condition of cloudy swelling.

\section{Inoculation of Animals.}

I. A guinea-pig inoculated subcutaneously with pure culture died on the seventh day.

The autopsy showed local inflammation at the seat of inoculation and the presence of a thick, cheesy material: There was enteritis; and the liver, spleen, lung, and kidneys were congested.

Smears from the local abscess and blood from the kidney showed the presence of the fungus.

Apparently the type of disease produced was an acute septicæmia.

2. A white rat inoculated subcutaneously with pure culture remained apparently healthy for thirty days save for the formation of a small local swelling. On the thirty-third day it died from other causes.

At the seat of inoculation an abscess was found containing a thick, sticky, cheese-like pus. The abscess measured $2 \mathrm{~cm}$. in length by about $5 \mathrm{~cm}$. in width.

No living organism could be found and cultures failed. Apparently the rat resisted infection.

3. Two camels were inoculated by scarification of the skin and rubbing in pure culture, the seat of inoculation being afterwards covered with sterile cotton. No reaction took place and the scarified areas healed rapidly.

4. Two camels were iroculated intravenously with I cc. each of pure culture emulsion in normal saline solution.

Camel No. I (Somali) developed at the seat of inoculation over the jugular vein a slowly-forming abscess which burst spontaneously on the eighteenth day. The pus on examination was not found to contain living streptothrix filaments, but only acid-fast spores. There was much granular detritus and unstained dead filaments. Cultures on agar grew well on the fourth day, with the typical appearance already described.

Apparently on withdrawing the needle at the time of inoculation a small quantity of culture had been left in the needle track.

On the fifty-first day the same camel was slaughtered, the animal's condition being then good.

The lungs were found to be filled with nodules similar to those described in the naturally occurring case, varying in size from a pea to a broad bean. The smaller nodules were nearly spherical, the larger more irregular in shape. There was evidence of a process of repair in the form of fibrous tissue formed around the nodules. Those situated immediately beneath the pleura produced a fibrous thickening of that membrane. Histologically they were similar to those described. 
The bronchial glands were hæmorrhagic, but showed no definite lesion.

The liver contained two nodules. Other organs normal. The seat of inoculation showed a slight scar but no other lesion; jugular vein normal.

Preparations made from the lung and liver lesions showed the acid-fast streptothrix in great quantity.

Cultures grown on agar from the lung and liver lesions had the typical appearance to the naked eye and microscope as described in the foregoing. There is no doubt that the disease was successfully reproduced, and that the causal organism was identical with the one found in the original case.

The second camel inoculated intravenously, beyond a transient temperature reaction, showed no reaction to the inoculation. There was no local abscess. It was slaughtered on the fifty-first day, and a careful autopsy failed to reveal any lesion due to the streptothrix.

\section{Natural Case, No. 2.}

On 8th June I9I8, the lungs of an Egyptian camel slaughtered for debility were received from Major D. S. Rabagliati for examination. In addition to numerous tubercle-like nodules, they were found to contain patchy areas of pneumonia following the distribution of the lobules, and a lesion containing a cheesy mass as large as a walnut. The bronchial glands were caseous.

Examination of the lesions showed that they contained an acidfast streptothrix which was morphologically and culturally identical with that found in the first case.

The patchy areas of consolidation were found to be lesions of broncho-pneumonia with the other pathological changes previously described, and contained the acid-fast streptothrix.

\section{Method of Natural Infection.}

Of the two cases under review the oldest lesions in the first were undoubtedly those found in the lungs, and in the second the lesions were limited to those organs and their glands.

This fact, taken into consideration with the complete desiccation which the spores are able to withstand, as shown by the experiments in vitro, makes it reasonable to conjecture that natural infection takes place by inhalation of the spores.

From its nature it would be reasonable to suppose that the streptothrix has its habitat outside the animal body, probably as a parasite on a cereal or grass, which when dried would reach the required degree of desiccation for the liberation of the minute spores.

\section{CONCLUSION.}

In the literature at my disposal I have been unable to trace any record of streptotrichosis in the camel, nor of any streptothrix having the peculiar characters above described.

In a report, dated March I908, and entitled Veterinary Notes on Kordofan Province, Captain A. J. Williams, R.A.V.C., shortly 
describes a lung disease of camels, locally called Guffar ${ }^{1}$ or Ghudad, in which tubercle-like lesions are found in the lungs.

He states, however, that examination of specimens at the Khartoum Laboratory showed that the disease was caused by a botryomyces, and therefore quite distinct from streptotrichosis.

The writer believes that he has described a streptotrichosis or pseudo-actinomycosis in the camel, caused by a species of streptothrix which has not previously been recorded, and he therefore proposes to name it the Streptothrix cameli.

\title{
OBSERVATIONS WITH REGARD TO THE ETIOLOGY OF JOINT-ILL IN FOALS.
}

\author{
By Sir John M'Fadyean, M.B., B.Sc., LL.D., and Captain \\ J. T. EDwards, M.R.C.V.S., B.Sc. \\ (From the Research Institute in Animal Pathology, Royal \\ Veterinary College, London.)
}

\section{Introduction.}

IN a previous article ${ }^{2}$ we described certain observations which we had been able to make with regard to the etiology of abortion in mares and joint-ill in foals, and came to the conclusion that the Bacillus abortivo-equinus was the organism commonly responsible for outbreaks occurring in Great Britain. We also placed on record the results obtained in nearly 200 cases of joint-ill or navel-ill which had been treated with a serum obtained from horses hyperimmunised with that bacillus, but were then unable to form a confident opinion with regard to the effect of this treatment, owing to (I) uncertainty as to the average mortality of joint-ill when not treated in any way, and (2) the possibility that the cases treated were heterogeneous in their nature.

It was then decided to continue the supply of serum during the following foaling season, but to make it a condition that veterinary surgeons who accepted it should, if possible, forward to us either the entire carcase or one or more of the affected joints in every case in which the foal died or had to be destroyed on account of joint-ill.

Under this arrangement we were fortunate enough to receive parts from over fifty foals, and the purpose of the present article is to describe the further light which a bacteriological examination of this material throws on the etiology of joint-ill.

It may here be said that the total number of doses of serum supplied gratis to members of the profession during the foaling season in I918 was 758, and that the number of reported deaths among the foals treated after the onset of symptoms of joint-ill was. 129. The fact is not mentioned to suggest any inference with regard to the value of the serum, but merely to show that a good

\footnotetext{
${ }^{1}$ In Egypt, Palestine, and Syria, "Guffar" or "Jaffar" is one of the names for trypanosomiasis.

" "Journal of Comparative Pathology and Therapeutics," Vol. XXX., 1917, pp. 321-365.
} 